\title{
Underwater Target Localization Using Opportunistic Ship Noise Recorded on a Compact Hydrophone Array
}

\author{
Mojgan Mirzaei Hotkani ${ }^{1, t, \ddagger(\mathbb{D})}$, Jean-Francois Bousquet ${ }^{2, \ddagger(\mathbb{D})}$, Seyed Alireza Seyedin ${ }^{1, *, \ddagger}$, Bruce Martin ${ }^{3, \ddagger}$ \\ and Ehsan Malekshahi ${ }^{2, \ddagger(D)}$ \\ 1 Department of Electrical Engineering, Ferdowsi University of Mashhad, Mashhad 9177948974, Iran; \\ m.mirzaei@mail.um.ac.ir or m.mirzaei@dal.ca \\ 2 Department of Electrical and Computer Engineering, Dalhousie University, Halifax, NS B3J 1B6, Canada; \\ jbousquet@dal.ca (J.-F.B.); Ehsan.Malekshahi@dal.ca (E.M.) \\ 3 JASCO Applied Sciences, 32 Troop Avenue, Suite 202, Dartmouth, NS B3B 1Z1, Canada; \\ bruce.martin@jasco.com \\ * Correspondence: seyedin@um.ac.ir; Tel.: +98-5138805132 \\ + Current address: Department of Electrical and Computer Engineering, Dalhousie University, \\ Halifax, NS B3J 1B6, Canada. \\ $\ddagger \quad$ These authors contributed equally to this work.
}

Citation: Mirzaei Hotkani, M.; Bousquet, J-F.; Seyedin, S.A.; Martin, B.; Malekshahi, E. Underwater Target Localization Using Opportunistic Ship Noise Recorded on a Compact Hydrophone Array. Acoustics 2021, 3, 611-629. https://doi.org/10.3390/ acoustics3040039

Academic Editor: Andrea Trucco

Received: 18 July 2021

Accepted: 27 September 2021

Published: 8 October 2021

Publisher's Note: MDPI stays neutral with regard to jurisdictional claims in published maps and institutional affiliations.

Copyright: (c) 2021 by the authors. Licensee MDPI, Basel, Switzerland. This article is an open access article distributed under the terms and conditions of the Creative Commons Attribution (CC BY) license (https:// creativecommons.org/licenses/by/ $4.0 /)$.

\begin{abstract}
In this research, a new application using broadband ship noise as a source-of-opportunity to estimate the scattering field from the underwater targets is reported. For this purpose, a field trial was conducted in collaboration with JASCO Applied Sciences at Duncan's Cove, Canada in September 2020. A hydrophone array was deployed in the outbound shipping lane at a depth of approximately $71 \mathrm{~m}$ to collect broadband noise data from different ship types and effectively localize the underwater targets. In this experiment, a target was installed at a distance $(93 \mathrm{~m})$ from the hydrophone array at a depth of $25 \mathrm{~m}$. In this study, a matched field processing (MFP) algorithm is utilized for localization. Different propagation models are presented using Green's function to generate the replica signal; this includes normal modes in a shallow water waveguide, the Lloyd-mirror pattern for deep water, as well as the image model. We use the MFP algorithm with different types of underwater environment models and a proposed estimator to find the best match between the received signal and the replica signal. Finally, by applying the scatter function on the proposed multi-channel cross correlation coefficient time-frequency localization algorithm, the location of target is detected.
\end{abstract}

Keywords: underwater acoustics; opportunity ship noise; compact array; matched field processing; multi-channel cross correlation coefficient; underwater localization; Lloyd-mirror pattern

\section{Introduction}

Nowadays, ocean acoustic scientists pay significant attention towards to the use of passive approaches instead of active techniques for ocean sensing due to the environmental regulations prohibiting the transmission of invasive noise source; passive sensing also reduces the cost and energy consumption for remote nodes. Furthermore, there has been a paradigm shift in ocean acoustics utilizing ambient noise as an opportunistic source. Opportunistic sources refer to acoustic energy existing in a maritime medium that has not been generated for the clear aim of ocean measurement. Wave noise and noise generated by sea ice and ships are known examples of acoustic sources of opportunity [1]. Additionally, ship noise can be considered as an active acoustic source for monitoring the ocean, despite its undesirable effects on the life of marine mammals. To date, a few studies have applied ship noise as an opportunistic active source to estimate the geoacoustic properties of the seabed using commercial or small ships [2-5]. Ships produce broadband noise at frequencies ranging from $20 \mathrm{~Hz}$ to $100 \mathrm{kHz}$, due to the hydrodynamics, on-board machinery, and more importantly, from propeller cavitation. The rotation of 
the blades around the propeller axis causes the cavitation phenomenon [6,7]. Specifically, the cavitation introduces a rapid change of pressure in a liquid, which leads to small vaporfilled cavity formations in places where the pressure is relatively low. At higher pressures, these cavities, called "bubbles" or "voids", collapse and can generate a high intensity shock wave. Cavitation depends on several factors, including the vessel size, its speed and load, the ocean conditions, the age of the vessel, the engine type, and the propeller size. As such, ships are powerful and underutilized acoustic sources of opportunity that can be used to obtain information about the marine environment and target localization [8].

The propagation of underwater acoustic is mathematically described by the wave equation and must take into consideration the appropriate boundary conditions which are unique to different environmental conditions. There are five methods to solve the propagation wave equation: the fast field program (FFP), normal modes, ray theory, the parabolic equation (PE), and finite element (FE) solution $[9,10]$. The choice of method depends on the application, the deployment geometry, and the frequency of operation. For example, matched field processing (MFP) when considering ray-theory as a replica signal creates misleading results at low frequencies [11].

A variety of techniques have been studied to localized the objects in the ocean. In [12], common approaches are reviewed to localize the sources with wireless sensor networks that utilize the intensity at the receiver, the time of arrival (ToA), the time difference of arrival (TDoA) [13], or the direction of arrival (DoA) which are obtained by combining the multiple sensor signals. However, other algorithms have been introduced recently. For example, in [14], the distributed sub-band valley fusion (DSVF) method is proposed for a multi-array system. The target position is estimated using the intersection of the bearing lines of the receiver arrays with respect to the target. For each array, the bearing line is extracted from the two-dimensional (2-D) $x-y$ steered response power (SRP) spectrum of the received signals of the array by implementing a 2-D sub-band valley energy detection (SVED) process. Additionally, in [15], a cluster-based direct source localization approach for large-aperture horizontal line arrays is proposed. Nonetheless, to localize the sources in complex media, MFP has been recognized as the most accurate technique and obtains an estimate of the source by matching the receive data at receivers and replica signals. In [16], an MFP method with measured replica fields is described, which provides instantaneous horizontal range estimates of a surface vessel in shallow water using a single hydrophone located above the sea bottom.

Popular techniques for localizing the underwater targets combine underwater wireless sensor networks (UWSNs) with active sonar systems [17]. Despite their effectiveness, these methods have many limitations. More importantly, the active source produces a negative impact on the hearing of marine mammals, particularly for those that use echolocalization to find their hunt. UWSN systems also have limitations, including energy consumption, channel capacity limitation, and low data rates. Additionally, the motion of the multiple sensors deployed sparsely reduces the accuracy of the target location estimation. The method that will be presented in this study is an opportunistic use of the ambient noise signals to identify the underwater targets; it does not suffer from these limitations, and the algorithm is completed using a single compact array equipped with a signal processing engine.

The focus of this research is to localize the target echo passively using ship noise. For this purpose, the MFP algorithm is utilized and combined with the scattering function according to a bistatic geometry in an isovelocity waveguide [18]. The isovelocity environment is justified for many deployment scenarios, and particularly in shallow water conditions. In these shallow conditions, the propagation can be represented using a waveguide, and the spatial complexities of the acoustic field are utilized in a MFP algorithm, which is a generalized beam-forming method to localize the active sources as a function of range, depth. Specifically, MFP is a spatial filter that compares the received signal and a replica signal modeled using Green's function in a waveguide [19]. It can be implemented using conventional or adaptive formulations for both narrowband and wideband signal 
models. Several of Green's formulations to construct the replica signal can be utilized, and the most common are normal modes in a shallow water waveguide, the Lloyd-mirror pattern, and the image model [11]. So, for localization purposes, using an accurate propagation model with an applicable localization method as an estimator is very important. The main purpose of this paper is to measure the return echo of the ship noise signal due to the reflection of the target surface, by utilizing a simple normal mode acoustic model to represent underwater propagation in shallow environments.

The main contributions of this work are two-fold. First, the opportunistic use of ship noise is described for the localization of a target; this technique avoids the generation of additional man-made acoustic signals that can threaten marine life. Second, a novel estimator using MFP is developed in this paper. The proposed estimator is based on the multi-channel cross-correlation coefficient (MCCC) localization algorithm. In the proposed algorithm, a time-domain cross-correlation matrix that contains the information of a specific frequency band is calculated, and the algorithm is optimized to reduce the number of mathematical operations on a real-time processor. The algorithm also takes into consideration the features of the propagation model. Furthermore, the algorithm is validated in a high-traffic shipping lane on the littoral of North America.

The structure of this paper is as follows: Section 2 describes theoretical background, such as the underwater acoustic propagation models and the scattered field from a target; Section 3 presents the methods and material including the proposed time-frequency MCCC algorithm to localize the underwater active source and experimental setup and dataset; Additionally, Section 4 demonstrates the performance of the proposed algorithm; finally, Section 5 highlights the conclusions of this work.

\section{Theoretical Background}

In this section, different approaches to model the acoustic propagation with different levels of complexity and scattering field from a target in a waveguide will be described. Specifically, in Section 2.1, a review of the Lloyd-mirror pattern will be provided; then, in Sections 2.2 and 2.3 will be described the image model, and the normal mode model, respectively; finally, in Section 2.4, will be explained the scattering field from the targets in a waveguide.

\subsection{The Lloyd-Mirror Pattern (LMP)}

In this section, the Lloyd-mirror pattern presented in [9] is reviewed. Let us assume that $S(\omega)$ is the value of a given acoustic source at an angular frequency $\omega$ and located at $p_{0}\left(x_{0}, y_{0}, z_{0}\right)$ on a Cartesian coordinate system. For a hydrophone array with $N$ elements, the received signal $H_{n}(\omega)$ at the $n^{\text {th }}$ element located at $p_{n}\left(x_{n}, y_{n}, z_{n}\right)$ has a relationship with $S(\omega)$ depending on the propagation model.

A LMP occurs when the acoustic source is located near the ocean surface and the ocean surface acts as a perfect reflector. Using LMP, the interference pattern in the acoustic field results from the constructive and destructive interference between the direct and source-reflected acoustic waves. Thus, the multipath is modeled using a direct and a reflected path from the ocean surface. As can be seen from Figure 1, there are two paths with lengths $R_{1}$ and $R_{2}$ in this model. Given a transmit signal with intensity $S(\omega)$ at frequency $\omega$, the received signal intensity is expressed as [9]

$$
H_{n}(\omega)=S(\omega) \cdot P\left(p_{0}, p_{n}, \omega\right)=-\frac{S(\omega)}{4 \pi} \cdot\left(\frac{\mathrm{e}^{-\mathrm{i} k R_{1}}}{R_{1}}-\frac{\mathrm{e}^{-\mathrm{i} k R_{2}}}{R_{2}}\right)
$$

where $f$ and $k$ are frequency and wave number, respectively. Additionally, the direct path length is $R_{1}=\sqrt{\left(x_{0}-x_{n}\right)^{2}+\left(y_{0}-y_{n}\right)^{2}+\left(z_{0}-z_{n}\right)^{2}}$, while the length of the path with a surface bounce is $R_{2}=\sqrt{\left(x_{0}-x_{n}\right)^{2}+\left(y_{0}-y_{n}\right)^{2}+\left(z_{0}+z_{n}\right)^{2}}$. 


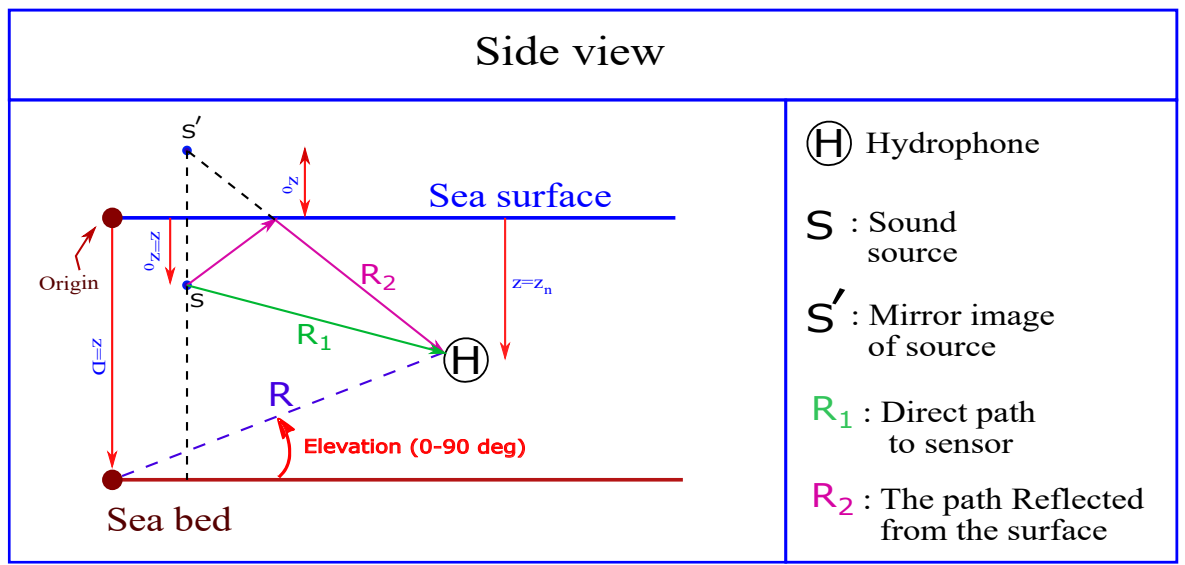

Figure 1. Schematic of the Lloyd-mirror pattern.

\subsection{The Image Model}

The image model is a generalized case of the LMP and takes into consideration multiple surface and bottom reflections. The image model contains multiple modes, and in this work each mode contains four paths. Figure 2 shows the paths for the mode $m=0$ in the image model.

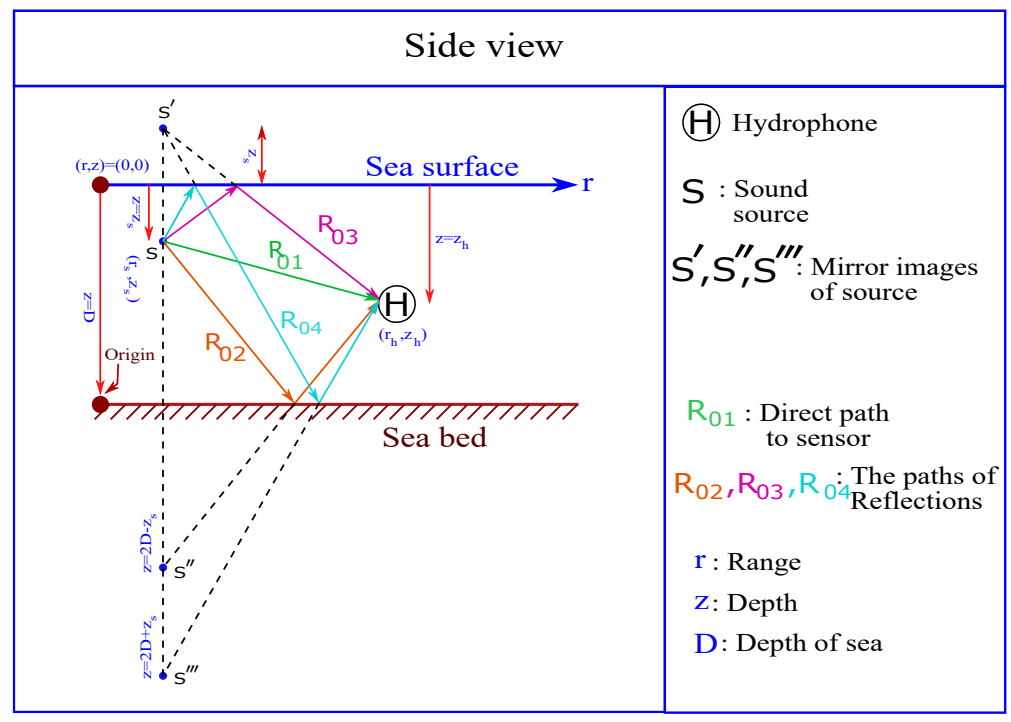

Figure 2. Representation of the multiple paths considered for the image model for $m=0$.

Using the image model, the relationship between the source signal $S(\omega)$ and the received signal $H_{n}(\omega)$ at the $n^{\text {th }}$ hydrophone at angular frequency $\omega$ is defined as

$$
\begin{aligned}
H_{n}(\omega) & =S(\omega) \cdot P\left(p_{0}, p_{n}, \omega\right)=-\frac{S(\omega)}{4 \pi} . \\
& \sum_{m=0}^{\infty}\left(\frac{\mathrm{e}^{-\mathrm{i} k R_{m 1}}}{R_{m 1}}-\frac{\mathrm{e}^{-\mathrm{i} k R_{m 2}}}{R_{m 2}}-\frac{\mathrm{e}^{-\mathrm{i} k R_{m 3}}}{R_{m 3}}+\frac{\mathrm{e}^{-\mathrm{i} k R_{m 4}}}{R_{m 4}}\right),
\end{aligned}
$$

where $m$ and $D$ are the mode number and depth of ocean, respectively. Additionally, for the $m$ th mode, the range for path $j=1, \ldots, 4$ between the source and hydrophone $n$th is $R_{m j}=\sqrt{\left(x_{0}-x_{n}\right)^{2}+\left(y_{0}-y_{n}\right)^{2}+z_{m j}^{2}}$. The depths $z_{m j}$ are for the $m$ th mode and for paths $j=1, \ldots, 4$.

$$
\begin{gathered}
z_{m 1}=2 m D-z_{0}+z_{n} \\
z_{m 2}=2(m+1) D-z_{0}-z_{n}
\end{gathered}
$$




$$
z_{m 3}=2 m D+z_{0}+z_{n},
$$

and

$$
z_{m 4}=2(m+1) D+z_{0}-z_{n}
$$

note that the location of the receiver and source are determined by $z$ and $z_{s}$, respectively.

\subsection{The Normal-Mode Model in an Isovelocity Environment}

The normal-modes model is a solution of the wave equation, defined as [9].

$$
\rho \nabla \cdot\left(\frac{1}{\rho} \nabla p\right)-\frac{1}{c^{2}} \frac{\partial^{2} p}{\partial t^{2}}=0,
$$

where $p, \rho, \nabla$, and $\partial$ are the acoustic pressure, the density of environment, the divergence operator, and the derivative operator, respectively. The following boundary conditions are assumed in this work:

1. A pressure release at the surface $(z=0)$;

2. A perfectly rigid bottom with lossless reflection at the sea bottom, i.e., when $z=D$.

Note that, on a first order approximation, this assumption is valid for the test conditions in this work since the bottom is rocky [9]. equal to

The general solution of the wave equation for solving the normal-mode problem is

$$
\begin{aligned}
H_{n}(\omega) & =S(\omega) \cdot P\left(p_{0}, p_{n}, \omega\right) \\
& =S(\omega) \cdot \frac{-\mathrm{i}}{\rho\left(z_{0}\right) \sqrt{8 \pi r}} e^{\mathrm{i} \pi / 4} \cdot \sum_{m=1}^{\infty}\left(\Psi_{m}\left(z_{0}\right) \Psi_{m}\left(z_{n}\right) \frac{e^{-\mathrm{i} k_{\mathrm{r} m} r}}{\sqrt{k_{\mathrm{r} m}}}\right),
\end{aligned}
$$

where $m, \rho\left(z_{0}\right), \Psi_{m}$ and $k_{\mathrm{r} m}$ are the mode number, the density of water at the depth of source, the mode function or eigen-function, and the horizontal wave number or eigenvalues, respectively.

In an isovelocity problem, the sound speed profile and density are constant. As such, the mode function is obtained according to

$$
\Psi_{m}(z)=\sqrt{\frac{2 \rho}{D}} \sin \left(k_{\mathrm{z} m} z\right),
$$

where $k_{\mathrm{z} m}, r$ and $D$ are the vertical wave number, the range between the array and source, and the depth of sea, respectively. The maximum number of propagation modes can be bound to a finite value [9], such that only modes which cause $k_{\mathrm{r} m}$ to be a real number are considered. Note that the $m^{\text {th }}$ mode has $m$ zeroes. Thus, the maximum number of modes for the frequency $f$ is determined as

$$
M<\frac{2 f D}{c}+\frac{1}{2} .
$$

Table 1 shows the conditions for the proposed deployment scenario in Duncan's Cove, on the littoral of Nova Scotia, Canada.

Table 1. The experimental conditions in Duncan's Cove.

\begin{tabular}{cc}
\hline Parameters & Values \\
\hline The sound speed & $c=1490.35 \mathrm{~m} / \mathrm{s}$ \\
Depth of water & $D=71 \mathrm{~m}$ \\
Depth of source & $z_{-} s=1.3 \mathrm{~m}$ \\
Depth of Receiver & $z_{-} r=70 \mathrm{~m}$ \\
The average source frequency & $f=1500 \mathrm{~Hz}$ \\
\hline
\end{tabular}


In this case study, there are 140 propagating modes. We also obtained the transmission loss for this environment which is defined by

$$
I(r, z)=-20 \log \left|\frac{1}{D} \sqrt{\frac{8 \pi}{r}} \sum_{m=1}^{\infty}\left(\Psi_{m}\left(z_{0}\right) \Psi_{m}\left(z_{n}\right) \frac{e^{-\mathrm{i} k_{\mathrm{r} m} r}}{\sqrt{k_{\mathrm{r} m}}}\right)\right|^{2}
$$

Using (7), Figure 3a shows the transmission loss as a function of range for a receiver when the depth of propeller, and the receiver depth are $1.3 \mathrm{~m}$ and $70 \mathrm{~m}$, respectively, using 140 modes. As can be observed, since the deployment scenario can be considered a waveguide, the modes form a multipath channel, which causes the transmission loss to vary significantly as a function of distance.

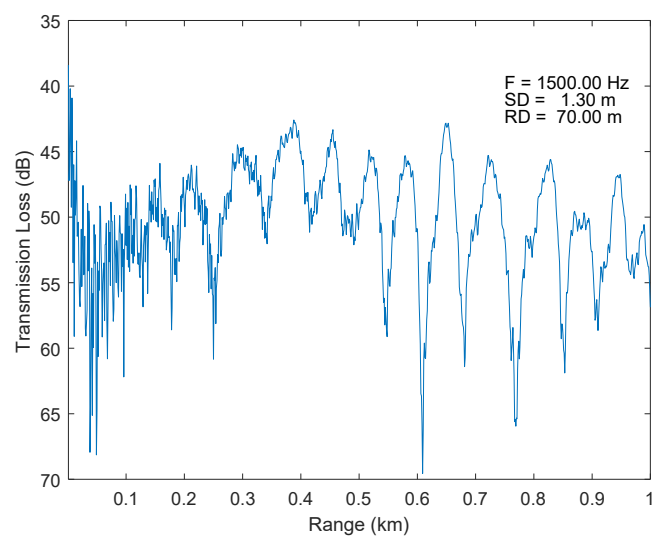

(a) The transmission loss based on the range

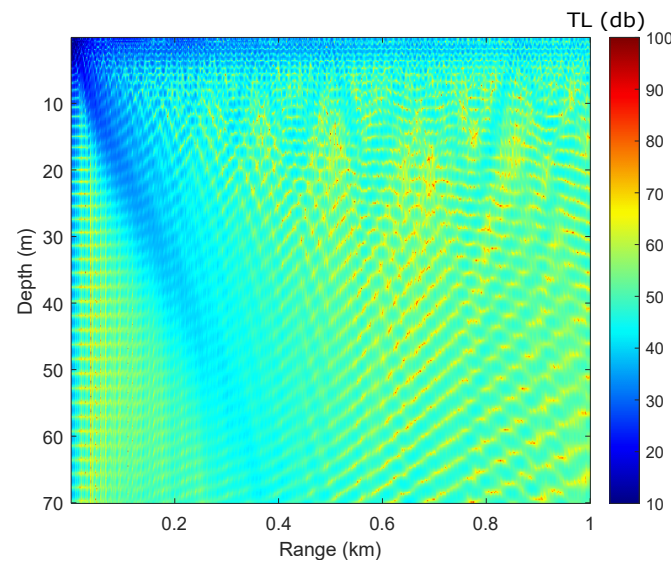

(b) The transmission loss versus range and depth.

Figure 3. Transmission loss for the experimental conditions obtained using Legendre-Galerkin with 140 modes.

To assess the feasibility of detecting a target that is deployed at different depths, the transmission loss between a potential target is also assessed as a function of depth and range. The simulations are done using the Legendre-Galerkin algorithm [20] to simulate the normal mode. Figure $3 b$ shows the signal attenuation. As can be observed, the blue color indicates the locations with the lowest transmission loss, and as will be demonstrated in Section 4, the target is more likely to be identified if located the blue area, near the ship.

\subsection{Scattering Field from Targets in a Waveguide}

In this section, Ingenito's solution [21,22] for the scattering problem from a spherical target based on the mode coupling method is reviewed. Additionally, using the planewave scattering function with specific boundary conditions in an isovelocity environment, the scattered field is obtained. The boundary conditions take into consideration the rigid or pressure-release boundary conditions, the continuity of pressure, and continuity for the normal particle velocity conditions. The geometry of the scattering problem is shown in Figure 4, where the surface and bottom of this isovelocity waveguide are at $z=-D$, and $z=H-D$ ( $H$ is the depth of water $)$, respectively. 


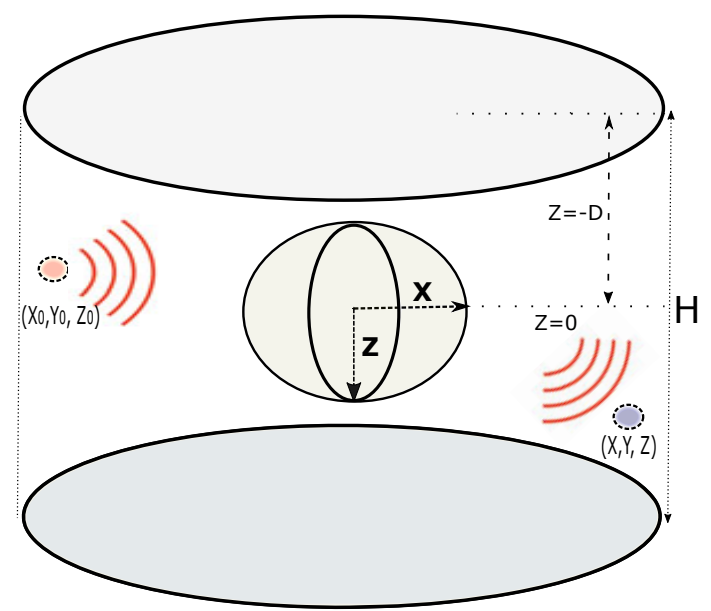

Figure 4. The geometry of scattering from the sphere target in a isovelocity waveguide of depth $\mathrm{H}$.

The origin of this system is assumed at the center of the target. The source is located at $\left(x_{0}, y_{0}, z_{0}\right)$ and the received field is assumed at $(x, y, z)$ while a point of the surface target at $\left(x^{\prime}, y^{\prime}, z^{\prime}\right)$ is encountered with the input field. The channel frequency response for the received scattering field using the mode-coupling method is modeled by

$$
P_{n}(\omega)=P_{n_{s t}}\left(p_{0}, p_{t}, \omega\right) P_{n_{t r}}\left(p_{t}, p_{n}, \omega\right)+P_{n_{s r}}\left(p_{0}, p_{n}, \omega\right),
$$

where $P_{s t}\left(p_{0}, p_{n}, \omega\right), P_{t r}\left(p_{0}, p_{n}, \omega\right)$, and $P_{s r}\left(p_{0}, p_{n}, \omega\right)$ are the acoustic channel response between the target and the source, the acoustic channel response between the target and receiver, and the acoustic channel response between the source and receiver, respectively. Additionally, the points $p_{0}=\left(r_{0}, \theta_{0}, \phi_{0}\right)$, and $p_{t}=\left(r_{t}, \theta_{t}, \phi_{t}\right)$ are the source point, and the target point, respectively in the spherical coordinates system. According to the Ingenito's solution and the near-horizontal propagation approximation, $B_{n}\left(r, r_{n}{ }^{\prime}, \phi_{0}, \phi, z_{t}\right)=$ $P_{n_{s t}}\left(p_{0}, p_{n}, \omega\right) P_{n_{t r}}\left(p_{0}, p_{n}, \omega\right)$ is equal to

$$
\begin{aligned}
& B_{n}\left(r, r_{n}{ }^{\prime}, \phi_{0}, \phi, z_{t}\right)=\frac{i}{2 k} S\left(\theta_{n}=0, \phi_{n} ; \theta_{0}=0, \phi_{0}\right) \times \\
& \sum_{m=1}^{\infty}\left(\Psi_{m}\left(z_{0}\right) \Psi_{m}\left(z_{t}\right) \frac{e^{-\mathrm{i} k_{\mathrm{r} m} r}}{\sqrt{k_{\mathrm{r} m} r}}\right) \sum_{m^{\prime}=1}^{\infty}\left(\Psi_{m^{\prime}}\left(z_{t}\right) \Psi_{m^{\prime}}\left(z_{n}\right) \frac{e^{-\mathrm{i} k_{\mathrm{r}_{\mathrm{n}}^{\prime} \prime^{\prime}} r_{n}{ }^{\prime}}}{\sqrt{k_{\mathrm{r}_{\mathrm{n}}^{\prime} m^{\prime}} r_{n}^{\prime}}}\right),
\end{aligned}
$$

where $S\left(\theta_{n}=0, \phi_{n} ; \theta_{0}=0, \phi_{0}\right), z_{t}, r, r_{n}^{\prime}$ are the far-field scattering function, the depth of the target, the range between the source and target, and the range between the target and receiver, respectively.

The far-field scattering function for a soft radius $a$ is expressed as

$$
S_{s o f t}\left(\theta_{m}, \phi_{m} ; \theta_{m^{\prime}}, \phi_{m^{\prime}}\right)=i \sum_{m} \frac{J_{n}(k a)}{H_{n}{ }^{(1)}(k a)}(-1)^{n}(2 n+1) P_{n}\left(\cos \beta_{m m^{\prime}}\right),
$$

while for the rigid sphere, the far-field scattering function is expressed as

$$
S_{\text {rigid }}\left(\theta_{m}, \phi_{m} ; \theta_{m^{\prime}}, \phi_{m^{\prime}}\right)=i \sum_{m} \frac{J_{n}^{\prime}(k a)}{H_{n}^{\prime}(1)(k a)}(-1)^{n}(2 n+1) P_{n}\left(\cos \beta_{m m^{\prime}}\right) \text {, }
$$

where

$$
\cos (\beta)=\sin (\theta) \sin \left(\theta_{0}\right)+\cos (\theta) \cos \left(\theta_{0}\right) \cos \left(\phi-\phi_{0}\right),
$$

and $J_{n}$ and $H_{n}$ are the spherical Bessel function, and Hankel function, respectively.

Using the normal mode model, the acoustic channel gain as a function of frequency between the source and receiver $P_{s r}\left(p_{0}, p_{n}, \omega\right)$ is calculated using (4). Figure 5 shows the far-field scattering function for both the rigid and soft target with a radius of $1 \mathrm{~m}$. 
The frequency of source, and the sound speed are $2.5 \mathrm{kHz}$, and $1490 \mathrm{~m} / \mathrm{s}$, respectively. Additionally, the source is located at a coordinate of $\left(\theta_{0}=315.01, \phi_{0}=0\right)$. As can be observed in Figure 5a, the scattering field of the soft target is smoother than for the rigid target. Additionally, the maximum field is aligned with the direction of the input source for the rigid and soft target.
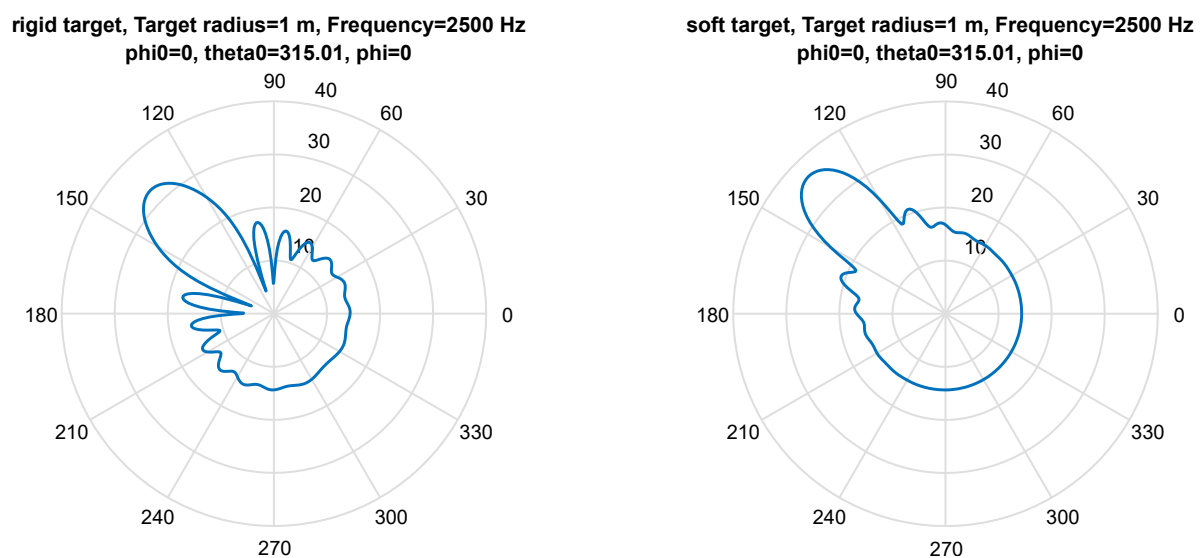

(a) The frequency of source and the radius of target are $2.5 \mathrm{kHz}$ and $1 \mathrm{~m}$, respectively.
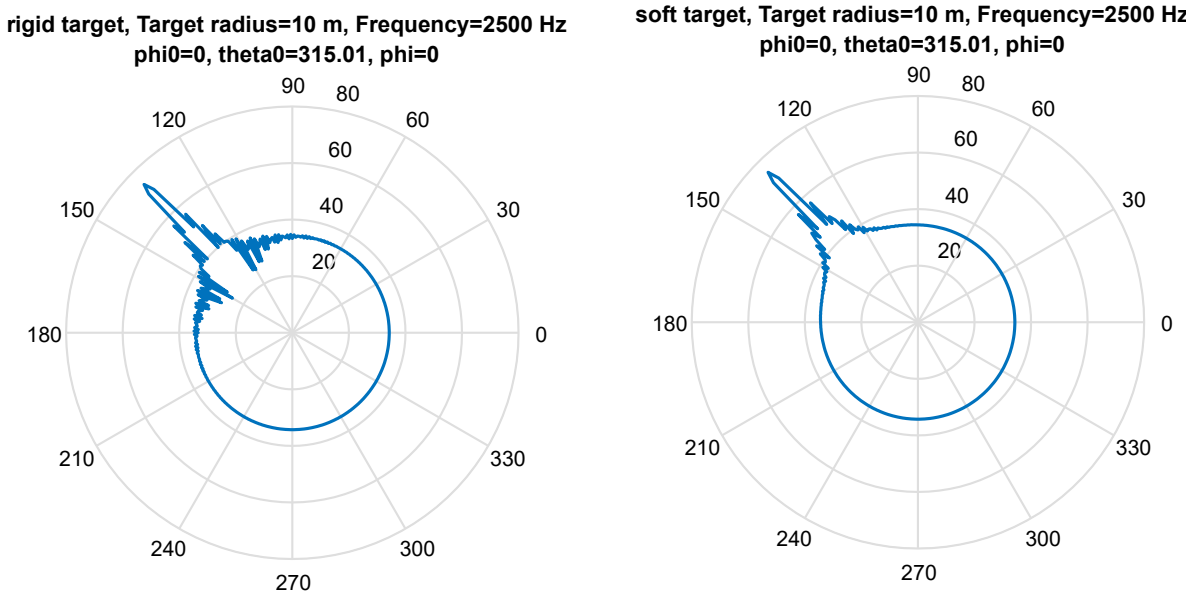

(b) The frequency of source and the radius of target are $2.5 \mathrm{kHz}$ and $10 \mathrm{~m}$, respectively.
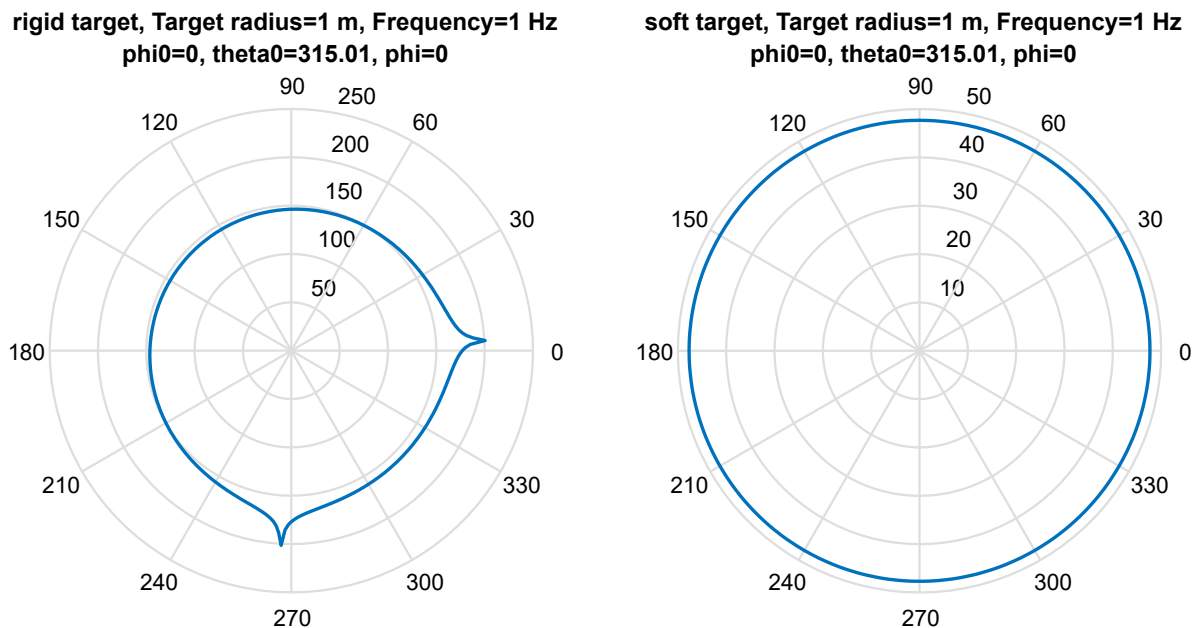

(c) The frequency of source and the radius of target are $1 \mathrm{~Hz}$ and $1 \mathrm{~m}$, respectively.

Figure 5. The far-field scattering function from the types of target by different frequencies of the source. 
A simulation for a target with a radius of $10 \mathrm{~m}$ is run to evaluate the effect of the target size on the scattering field. As shown in Figure $5 b$, it is obvious that the scattering field intensity is improved by about $10 \mathrm{~dB}$ by increasing the radius of the target by a factor of 10 . Additionally, the directivity of the scattered field is increased in comparison to a smaller target. The effect of the frequency on the scattering field is also validated by simulation. Figure $5 \mathrm{c}$ shows the scattered field for a low frequency source at $1 \mathrm{~Hz}$. According to the simulation results, the low-frequency source generates a stronger scattering field than the high-frequency source, and the field is broadcast in all directions uniformly.

\section{Methods and Material}

The proposed estimator for MFP and experimental dataset have been presented in Sections 3.1 and 3.2, respectively.

\subsection{Proposed Localization Algorithm for MFP}

The proposed algorithm is based on the multi-channel cross correlation coefficient (MCCC) localization algorithm [23]. MCCC is a time-domain approach to estimate the time delay of arrival (TDOA) in environment when the hydrophone (or microphone) array has more than two elements. Assume that $s\left(t_{k}\right)$ is the time value of a given narrowband acoustic source at time $t_{k}$, and is located at the point $p_{0}=\left(x_{0}, y_{0}, z_{0}\right)$ in the Cartesian coordinate system. This value is received at the $n^{\text {th }}$ hydrophone with the location $p_{n}=\left(x_{n}, y_{n}, z_{n}\right)$ at the time $t_{k}+\tau_{n}$. Thus, for a hydrophone array with $N$ elements in a noiseless free space, the received signal from single path at the $n^{\text {th }}$ element at time $t$ is calculated as

$$
r_{n}(t)=\alpha\left(p_{0}, p_{n}\right) \cdot s\left(t-\tau_{n}\left(p_{0}\right)\right),
$$

where $\alpha\left(p_{0}, p_{n}\right)$ is the loss, $\alpha\left(p_{0}, p_{n}\right) \in\left\{\mathbb{R} \mid 0 \leq \alpha\left(p_{0}, p_{n}\right) \leq 1\right\}$. Additionally,

$$
\tau_{n}\left(p_{0}\right)=\frac{\sqrt{\left(x_{0}-x_{n}\right)^{2}+\left(y_{0}-y_{n}\right)^{2}+\left(z_{0}-z_{n}\right)^{2}}}{c},
$$

where $c$ is the sound speed. One can estimate the transmit signal $s_{n}\left(t_{k}, p_{0}\right)$ from hydrophone $n$ as

$$
s(t)=\frac{r_{n}\left(t+\tau_{n}\left(p_{0}\right)\right)}{\alpha\left(p_{0}, p_{n}\right)} .
$$

The measured signals are modeled by $r_{n}\left(t_{k}\right), n=1,2, \ldots, N$ at discrete time $t_{k}=t_{\min }+k \Delta t$, where $\Delta t$ is the sampling time $k=0,1, \ldots, L-1$, and $s_{n}\left(t_{k}, \tilde{p}_{0}\right)$ is the discrete-time transmit signal at position $\tilde{p}_{0}$. If the point $\tilde{p}_{0}=\left(\tilde{x}_{0}, \tilde{y}_{0}, \tilde{z}_{0}\right)$ is the correct location of the source then all $N$ values $s_{n}\left(t_{k}, \tilde{P}_{0}\right), n=1,2, \ldots, N$ are almost completely correlated with each other at the time $t_{k}$. Considering the different propagation models defined, one can represent the transmit signal in the frequency domain as

$$
S(\omega)=R_{n}(\omega) \cdot P^{-1}\left(p_{0}, p_{n}, \omega\right) .
$$

Note that $R_{n}(\omega)$ is the $l^{\text {th }}$ frequency component of the FFT of the measured time signal $r_{n}\left(t_{k}\right)$, and $P\left(p_{0}, p_{n}, \omega\right)$ is the channel impulse response that is obtained according to the underwater acoustic propagation model (for example using the image model or the Lloyd-mirror pattern) between the source position $p_{0}$, and the sensor at position $p_{n}$. The discretized frequency samples are equal to

$$
\omega_{l}=l \Delta \omega, \quad l=0,1, \ldots,\left\lfloor\frac{L}{2}-1\right\rfloor, \Delta t \Delta \omega=\frac{2 \pi}{L},
$$

where $\lfloor$.$\rfloor denotes the floor value of its argument, also, L$ is the length of signal. Because the signal is a real value, only half of the signal is considered. 
Let us define $\overline{\boldsymbol{s}}\left(t_{k}, p\right)=F^{-1}[\overline{\boldsymbol{S}}(\omega, p)]$, where

$$
\bar{S}(\omega, p)=\left[\frac{R_{1}(\omega)\left|P\left(p, p_{1}, \omega\right)\right|}{P\left(p, p_{1}, \omega\right)} \ldots \frac{R_{N}(\omega)\left|P\left(p, p_{N}, \omega\right)\right|}{P\left(p, p_{N}, \omega\right)}\right]
$$

is the FFT of $\overline{\boldsymbol{s}}\left(t_{k}, p\right)$, Note that $|$.$| denotes the absolute value of its argument. From [9],$ the IFFT of is defined as $\overline{\boldsymbol{S}}(\omega, p)$ is defined as

$$
\overline{\boldsymbol{s}}\left(t_{k}, p\right)=\frac{\Delta \omega}{2 \pi} \operatorname{Re}\left\{\sum_{l=0}^{\frac{L}{2}-1}\left(\epsilon_{l} \overline{\boldsymbol{S}}\left(\omega_{l}, p\right) \mathrm{e}^{-\mathrm{i} \omega_{l} t_{\min }} \mathrm{e}^{-\mathrm{i} \frac{2 \pi l k}{L}}\right)\right\},
$$

where $\operatorname{Re}\{$.$\} denotes the real part of its argument. Additionally, \epsilon_{0}=1$, and $\epsilon_{l}=2$ for $l>0$. Then, one can represent (16) as

$$
\overline{\boldsymbol{s}}\left(t_{k}, p\right)=\sum_{l=0}^{\frac{L}{2}-1}\left(\left[\operatorname{Re}\left\{\boldsymbol{T}_{\mathbf{1}}(l, p)\right\}\right]\left(\operatorname{Re}\left\{T_{2}(l, k)\right\}\right)-\left[\operatorname{Im}\left\{\boldsymbol{T}_{\mathbf{1}}(l, p)\right\}\right]\left(\operatorname{Im}\left\{T_{2}(l, k)\right\}\right)\right),
$$

where $\operatorname{Im}\{$.$\} denotes the imaginary part of its argument, and$

$$
\left\{\begin{array}{l}
T_{1}(l, p)=\frac{\Delta \omega}{2 \pi} \epsilon_{l} \bar{S}\left(\omega_{l}, p\right) \mathrm{e}^{-\mathrm{i} \omega_{l} t_{\min }}, \\
T_{2}(l, k)=\mathrm{e}^{-\mathrm{i} \frac{2 \pi l k}{L}}
\end{array}\right.
$$

By calculating (17) in a specific frequency range for specific values of $l \in\{0,1, \ldots,(L / 2)-1\}$, that are corresponding to prefixed frequencies. The frequency limited time-domain crosscorrelation matrix can be simplified to

$$
\begin{aligned}
\boldsymbol{C}_{c}(p) \approx & \frac{1}{L} \sum_{l_{f}}\left(\operatorname{Re}\left\{\boldsymbol{T}_{\mathbf{1}}\left(l_{f}, p\right)\right\}^{\top} \operatorname{Re}\left\{\boldsymbol{T}_{\mathbf{1}}\left(l_{f}, p\right)\right\} \times \sum_{k=0}^{L-1}\left(\operatorname{Re}\left\{T_{2}\left(l_{f}, k\right)\right\}\right)^{2}\right. \\
& -\left[\left[\operatorname{Re}\left\{\boldsymbol{T}_{\mathbf{1}}\left(l_{f}, p\right)\right\}\right]^{\top}\left[\operatorname{Im}\left\{\boldsymbol{T}_{\mathbf{1}}\left(l_{f}, p\right)\right\}\right]+\left[\operatorname{Im}\left\{\boldsymbol{T}_{\mathbf{1}}\left(l_{f}, p\right)\right\}\right]^{\top}\left[\operatorname{Re}\left\{\boldsymbol{T}_{\mathbf{1}}\left(l_{f}, p\right)\right\}\right]\right] \times \\
& \sum_{k=0}^{L-1} \operatorname{Re}\left\{T_{2}\left(l_{f}, k\right)\right\} \operatorname{Im}\left\{T_{2}\left(l_{f}, k\right)\right\}+\left[\operatorname{Im}\left\{\boldsymbol{T}_{\mathbf{1}}\left(l_{f}, p\right)\right\}\right]^{\top}\left[\operatorname{Im}\left\{\boldsymbol{T}_{\mathbf{1}}\left(l_{f}, p\right)\right\}\right] \times \\
& \left.\sum_{k=0}^{L-1}\left(\operatorname{Im}\left\{T_{2}\left(l_{f}, k\right)\right\}\right)^{2}\right),
\end{aligned}
$$

where $\boldsymbol{C}_{c}(p)=\frac{1}{L} \sum_{k=0}^{L-1}\left(\overline{\boldsymbol{s}}^{\top}\left(t_{k}, p\right) \overline{\boldsymbol{s}}\left(t_{k}, p\right)\right)$, is the cross-correlation matrix. Finally, the location of the source is estimated using [9]

$$
\hat{p}_{0}=\arg \min _{p}\left\{\operatorname{det}\left[\boldsymbol{C}_{c}(p)\right]\right\},
$$

In the proposed algorithm, a time-domain cross-correlation matrix which contains the information of specific frequency band is calculated using an approximation on the inverse fast Fourier transform (IFFT). The proposed method, in addition to taking advantages of both time and frequency-domain methods, also considers the features of the propagation model of the environment. This is a very important feature particularly in a shallow water environment, in which the received signal arrives at the receiver through multiple paths. Indeed, using a propagation model that considers other paths in addition to the direct path improves the underwater localization accuracy. The proposed method can be used with different propagation models, such as the Lloyd-mirror, image, and normal-modes. 


\subsection{Experimental Setup and Data Collection}

The acoustic data analyzed in this paper were produced by ships and were collected over 21 days. The experiment was conducted in collaboration with JASCO Applied Sciences in September 2020 in Duncan's Cove, Nova Scotia, Canada. A map showing the location of the hydrophone array and target, as well as the boundary for the shipping lanes are shown in Figure 6.

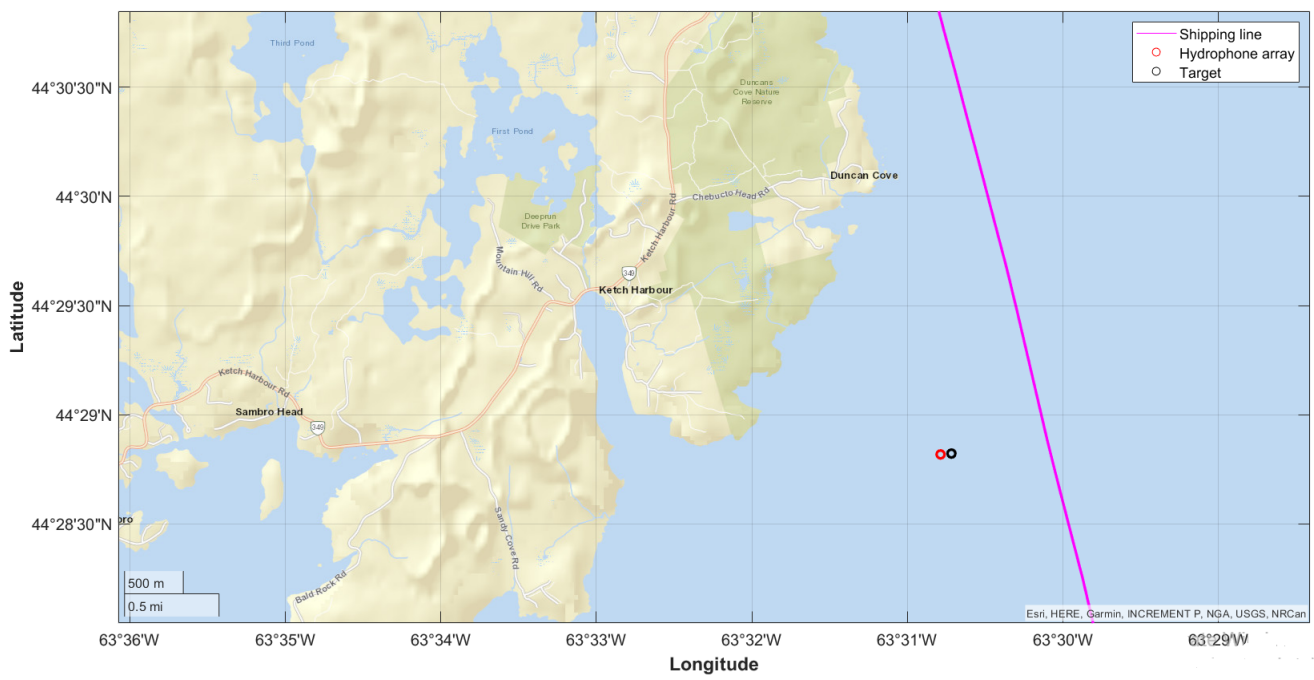

Figure 6. Map of the field trial area.

A 4-element hydrophone array was placed at approximately $900 \mathrm{~m}$ away from the outbound traffic lanes, and the target was at a range of $93 \mathrm{~m}$ from the hydrophone array, between the hydrophone and the shipping lanes. The exact location of target and hydrophone array is shown in Table 2. The geometry of the hydrophone array was designed, such that three hydrophones formed a planar array, while the fourth hydrophone was placed above one of the hydrophones on the planar array, such that they formed together a 2-element vertical array.

Table 2. The exact location of target and hydrophone array.

\begin{tabular}{cccc}
\hline & Latitude & Longitude & Depth \\
\hline Target & 44.480366 & -63.51195 & $25 \mathrm{~m}$ \\
Hydrophone array & 44.4803 & -63.513115 & $70 \mathrm{~m}$ \\
\hline
\end{tabular}

During the trials, the depth of water was $71.6 \mathrm{~m}$ but the tidal conditions caused changes in the water depth on different days as can be observed in Figure 7 where the variation of depth over time is offset from the location of the depth logger. Note that on 23 September 2020, Hurricane Teddy affected the depth log and acoustic data, which was discarded during this period. Because the depth is not constant over time, it should be noted that the propagation environment is not entirely static. The target is made of four 17-inch glass spheres from Vitrovex. They are mounted as pairs in two SUBS C-2 streamlined floats, that were joined together and installed at a depth $25 \mathrm{~m}$. This experiment was run for 21 days from 8 September to 29 September 2020. Several vessels passed during this period and their noise was recorded by the hydrophone array. 
Automatic Identification System (AIS) data was purchased from Marine Traffic (https:/ / www.marinetraffic.com/, accessed on 27 January 2021) within the limited experimental area to obtain the exact position of each passing ship over the experimental area for the proposed experiment.

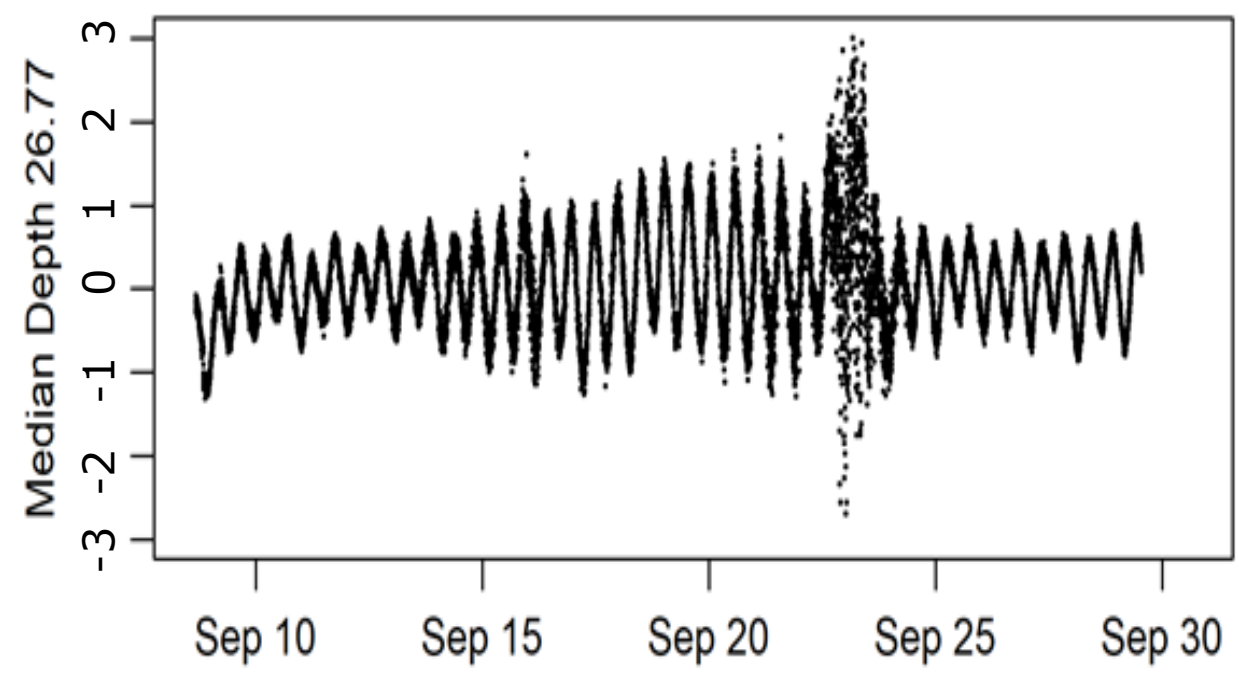

Figure 7. The changes in water depth over the 21 days of deployment.

\section{Simulation Results}

\section{Simulation Using the Synthetic Data}

Prior to the deployment, different scenarios were modeled to assess the localization algorithm in realistic environment conditions. The purpose of doing the pre-tests is to evaluate the ambiguity function in different areas if the target is in those areas.

Figure 8 presents the simulated ambiguity functions for the different scenarios. In these simulations, the parameters, such as the position of the source (the ship propeller), the position of the receiver, the size of the target, the frequency of the emitted signal from source, and the number of modes, are assumed to be known. Then, the most likely situations in which the target can be detected are identified by simulating (9) for each point in space. The simulation results for six different scenarios demonstrate the best position for the target location, i.e., where the ambiguity surface has the most energy. It can be observed that the target should be located on the transmitter-receiver line to be most likely detected. Additionally, other parameters such as the target radius and depth of the target in water can affect the maximum energy of the ambiguity function. Specifically, as the target size increases, and as it is deployed closer to the surface, the far-field scattered acoustic pressure increases.

The main purpose of this paper is to localize an underwater target due to propeller noise scattered from the target surface. As such, the propeller ship noise acts as the active sonar probing sequence. To estimate the position of the target, the received scattering field at the hydrophone array is processed using the algorithms described in Section 2.4. The target localization procedure (by MATLAB) is summarized as shown in Figure 9. First, the received signals at the hydrophones are converted to the frequency domain using a discrete-time Fourier transform. Then, the replica signal and the suggested underwater channel defined by (8) are modeled using different models of the acoustic propagation media. Finally, by sweeping the space, the position of the target is determined. 
(a)
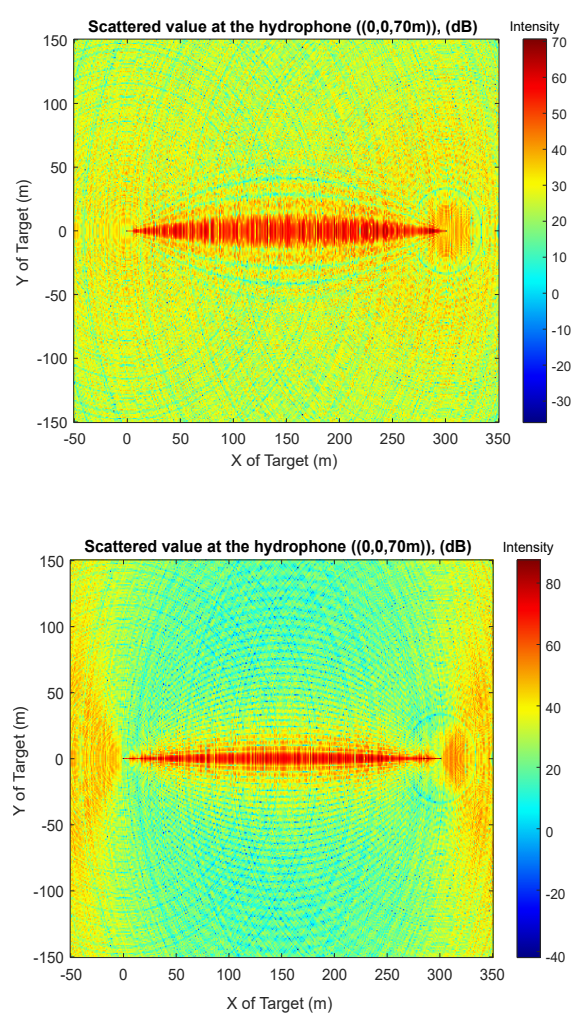

(d) (b)
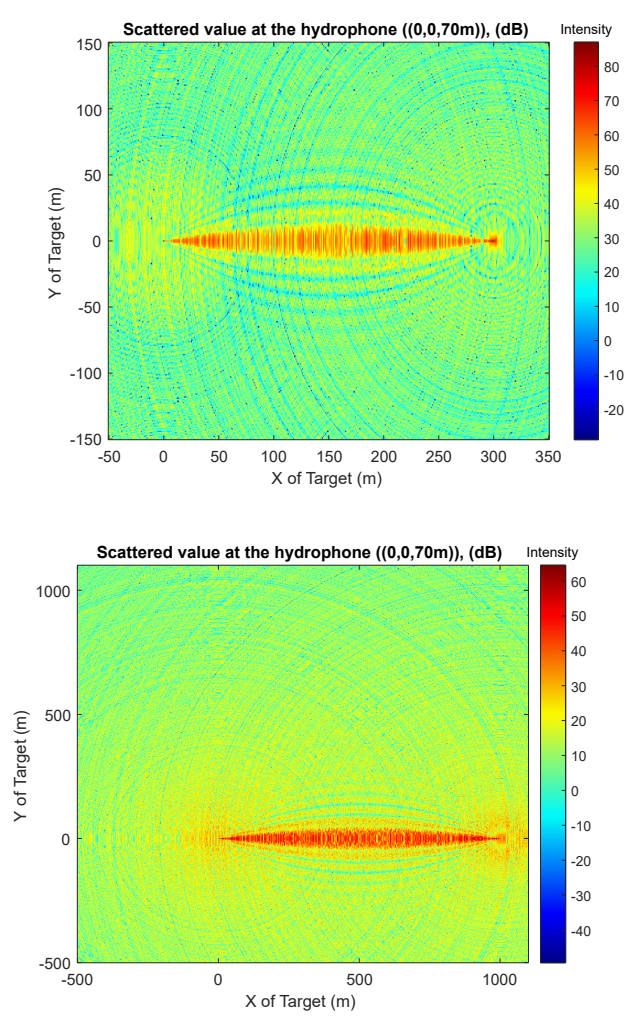

(e) (c)

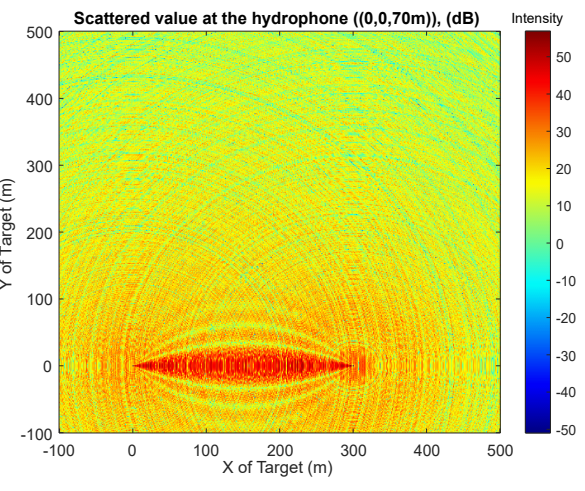

(f)

Figure 8. The far-field scattered acoustic pressure in the waveguide for six different scenarios. (a) The transmitter and receiver are located at $(x=300 \mathrm{~m}, y=0, d=0.5 \mathrm{~m})$, and $(x=0, y=0, d=70 \mathrm{~m})$, respectively. The depth of water, depth of target, the radius of target, and the average frequency of the propagated signal of source are $70 \mathrm{~m}, 25 \mathrm{~m}, 2 \mathrm{~m}$, and $2500 \mathrm{~Hz}$, respectively. (b) same parameters as (a) with the exception that the depth of the target is $0.5 \mathrm{~m}$; (c) same parameters as (a) with the exception that the radius of target is $1 \mathrm{~m}$; (d) same parameters as (a) with the exception that the radius of target is $10 \mathrm{~m}$; (e), same parameters as (a) with the exception that the location of transmitter is $(x=1000 \mathrm{~m}, y=0, d=0.5 \mathrm{~m})$; (f), same parameters as (a) with the exception that the location of transmitter and the radius of target are $(x=1000 \mathrm{~m}, y=0, d=0.5 \mathrm{~m})$ and $0.5 \mathrm{~m}$, respectively.

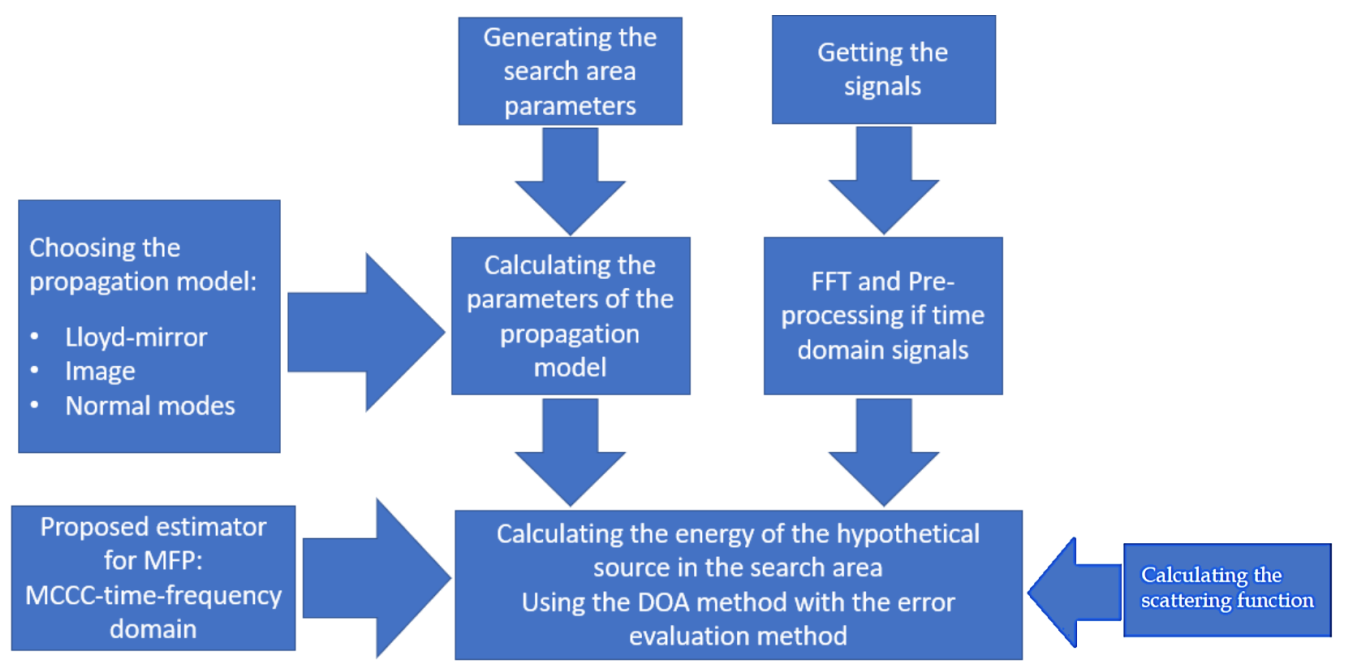

Figure 9. The procedure of target localization using the scattering field.

In this paper, we use the ship noise that was recorded on September 8 and 10 to evaluate the accuracy of the localization algorithm. First, JASCO's vessel present during 
the deployment on September 8 is used as a source of opportunity. The vessel is also tracked using the AIS data to provide a reference location.

To localize the underwater target in a pseudo-active manner using existing ambient signals as a source, the acoustic signal produced by the vessel, combined with the scattering signal at the hydrophone array, is recorded. By post-processing the data, the received filtered signal is applied to the algorithm solving (8) to evaluate the estimator accuracy based on using different acoustic propagation models. The parameters used for the simulation are given in Table 3. According to the simulation results presented in Section 4, the best scenario for identifying the target position is to place the array, the target and the source (propeller) along a straight line. So, when the ship is located at $(x=442.7 \mathrm{~m}, y=22.7 \mathrm{~m}, z=1.2 \mathrm{~m})$, the target localization algorithm is run using the received signals at the recorder. Figure 10a shows the result simulating the proposed time-frequency MCCC estimator using the normal-mode model as the underwater acoustic propagation model. The white square in this figure shows the maximum value of energy on this ambiguity plot. This localization value for the target is estimated at a range of $93.6 \mathrm{~m}$ from the array and at a depth of $24.8 \mathrm{~m}$ below sea surface. This demonstrates the accuracy of the target localization algorithm. Additionally, Figure 10b indicates the accuracy of the target localization algorithm for the proposed time-frequency MCCC estimator using the image model with four paths. The maximum in this case is estimated at a distance of $91.4 \mathrm{~m}$ of the array. In comparison, the estimated value calculated using the Lloyd-mirror model produces an estimate of $116.1 \mathrm{~m}$, as shown Figure 10c. The reason for this difference in the estimated values can be explained by the inaccuracy of Lloyd-mirror's model as an underwater acoustic propagation model, and specifically because the Lloyd-mirror pattern models multipath using only two paths. In comparison, the normal mode model considers the characteristics of the underwater environment such as water velocity (albeit assumed to be constant in this shallow environment) and density in addition to the multipath effect.

Table 3. Parameters needed to localize the target using JASCO's ship noise.

\begin{tabular}{cc}
\hline Parameters & Values \\
\hline Target diameter & $1.6 \mathrm{~m}$ \\
The actual range of the target from the array & $93 \mathrm{~m}$ \\
Depth of the target position from the ocean surface & $25 \mathrm{~m}$ \\
Type of the target & Rigid \\
Depth of ocean & $71.625 \mathrm{~m}$ \\
Maximum number of polynomials in Legendre function & 15 \\
Number of normal modes & 80 \\
Number of paths used in the image model & $4 \mathrm{paths}$ \\
Sound speed in ocean & $1490 \mathrm{~m} / \mathrm{s}$ \\
Sound speed on seabed & $1600 \mathrm{~m} / \mathrm{s}$ \\
Desired frequency range & $500-2000 \mathrm{~Hz}$ \\
Density of water & $1000 \mathrm{~kg} / \mathrm{m}^{3}$ \\
\hline
\end{tabular}

In Table $4, z$ represents the estimated depth of the target. Additionally, the horizontal range and the radial range (the radial range is the distance between the hydrophone array and the estimated target location) are, respectively, calculated as $\sqrt{x^{2}+y^{2}}$ and $\sqrt{x^{2}+y^{2}+\left(z-z_{h}\right)^{2}}$, where $z_{h}$ is the depth of the hydrophone array (which is $70 \mathrm{~m}$ ). Furthermore, the relative error is the absolute error divided by the magnitude of the true value. 


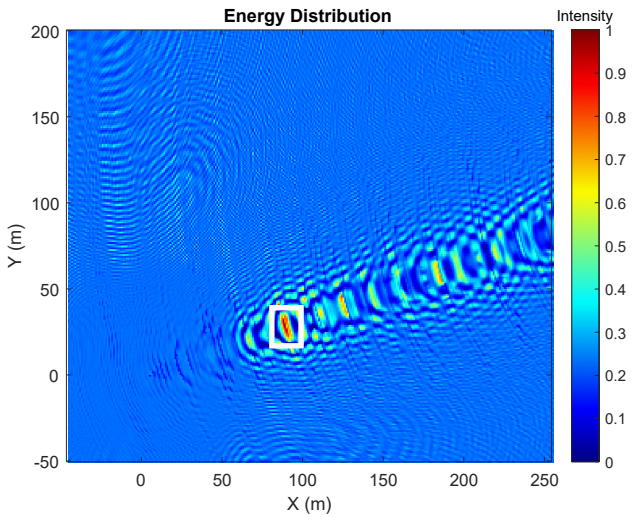

(a)

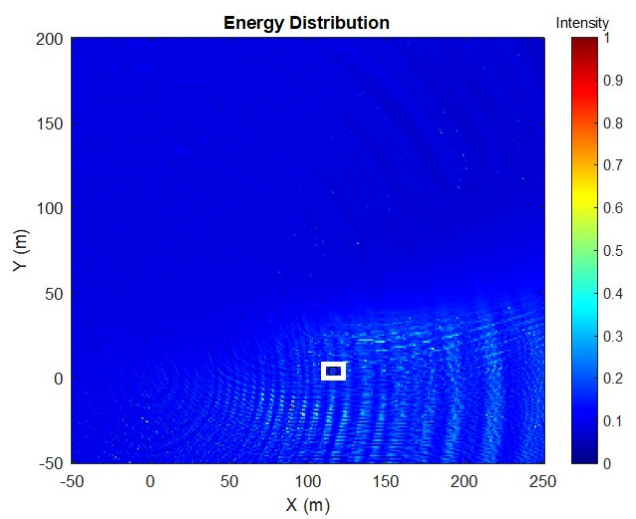

(c)

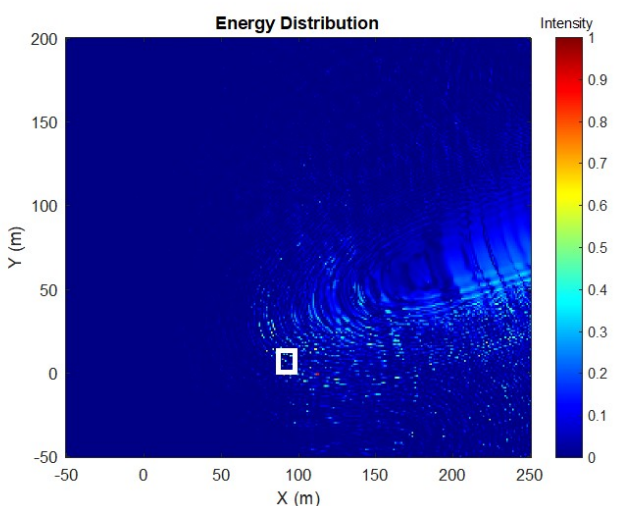

(b)

Figure 10. Ambiguity surface of MFP using the proposed estimator and different propagation models. The boxed area shows the maximum scattering energy at a depth of $24.8 \mathrm{~m}$. (a) Ambiguity surface of MFP with Normal-mode model. (b) Ambiguity surface of MFP with image model. (c) Ambiguity surface of MFP with Lloyd-mirror pattern.

Table 4. The estimated location of the target by the proposed estimator with different models for JASCO's ship noise.

\begin{tabular}{cccc}
\hline Propagation Model & $\begin{array}{c}\text { Estimated Target } \\
\text { Location }(\mathbf{x}, \mathbf{y}, \mathbf{z})\end{array}$ & $\begin{array}{c}\text { The Horizontal } \\
\text { Range Relative Error }\end{array}$ & $\begin{array}{c}\text { The Radial Range } \\
\text { Relative Error }\end{array}$ \\
\hline Normal-mode & $(89 \mathrm{~m}, 29 \mathrm{~m}, 24.8 \mathrm{~m})$ & $0.68 \%$ & $0.63 \%$ \\
Image & $(91 \mathrm{~m}, 9 \mathrm{~m}, 24.8 \mathrm{~m})$ & $1.64 \%$ & $1.24 \%$ \\
Lloyd-mirror & $(116 \mathrm{~m}, 5 \mathrm{~m}, 24.8 \mathrm{~m})$ & $24.88 \%$ & $20.62 \%$ \\
\hline
\end{tabular}

Secondly, to confirm the validity of the obtained results, the algorithm is validated on 10 September 2020 using the CMA CGM BRAZIL shown in Figure 11. The CMA CGM BRAZIL is one of the world's biggest cargo ships which berthed in Halifax's harbor on 10 September 2020. This ship can carry 15,000 containers and is $366 \mathrm{~m}$ in length and $51 \mathrm{~m}$ wide. Since it passed in the predefined zone of the AIS data collected, it was possible to track its position. 


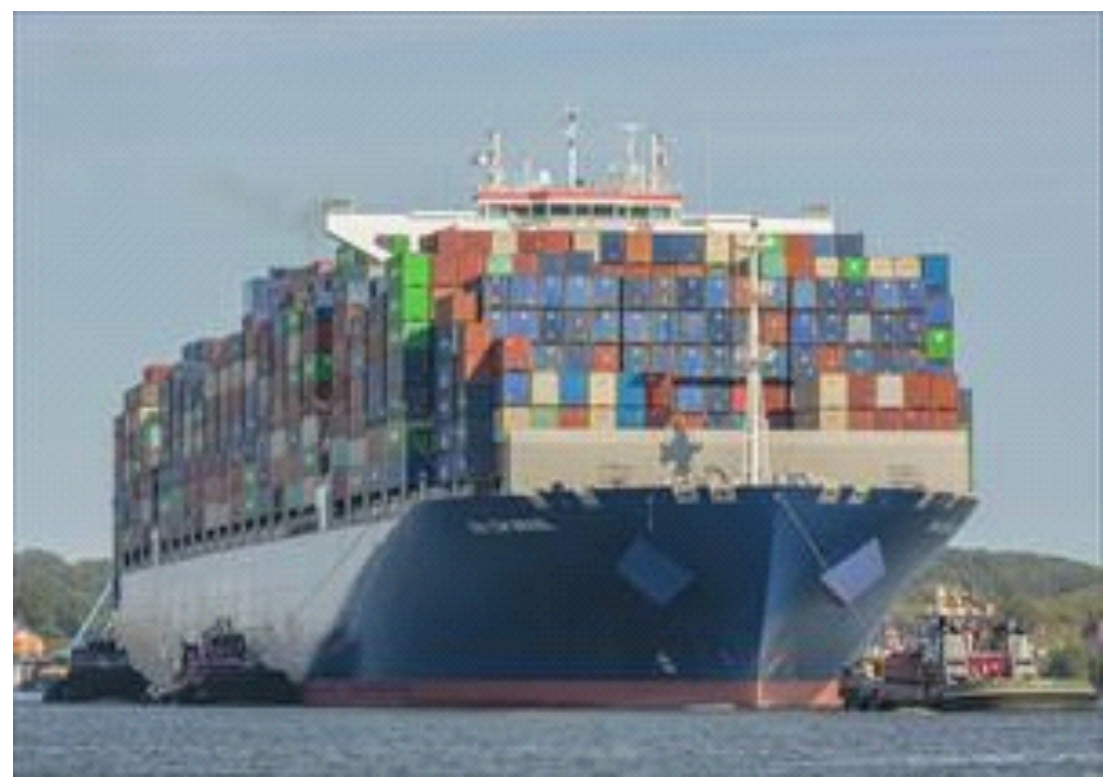

Figure 11. Container ship, CMA CGM BRAZIL.

This ship was at approximately $1 \mathrm{~km}$ from the hydrophone array, as it was navigating towards the port of Halifax. We recorded its position to be at $(x=907 \mathrm{~m}, y=130 \mathrm{~m}$, $z=1.9 \mathrm{~m}$ ), with respect to the array location. Using normal mode and the scattering model, the target location is estimated. In this test, the desired frequency band is between $500 \mathrm{~Hz}$ and $1500 \mathrm{~Hz}$. Other simulation parameters are summarized in Table 3. As shown in Figure 12a, the maximum energy is obtained for a location of $(x=88 \mathrm{~m}, y=4 \mathrm{~m})$, so the estimated range of target from the hydrophone array is approximately $88 \mathrm{~m}$.

The reason for the slight difference in the value of actual range from the estimated one can be due to the imprecision in the actual distance of the ship propeller from the array, as well as the limited accuracy that can be obtained with only two vertical elements in the array configuration.

Next, an attempt is done to estimate the location of the target using the image model and Lloyd-mirror pattern with the data collected. Figure $12 b, c$ show the ambiguity function for the image model and Lloyd-mirror pattern, respectively. In this case, the maximum is estimated at a location near the hydrophone array instead of the target, but a yellow area (at a range of about $91 \mathrm{~m}$ ) is seen at the location of the target on the ambiguity surface. This confirms the importance of an accurate propagation model to estimate the location of the target.

Table 5 shows the estimated location for the target by considering two maximum values, the global or the first local maximum point (shown by the superscript (F)), and the second local maximum point (shown by the superscript (S)). The purpose of this Table is to show the superiority of the normal-mode model over the image and Lloyd-mirror models in the MFP method in this case. However due to the Figure 12b,c and Table 5, the image and Lloyd-mirror models have a good estimation of the target location if the second local maximum point (the yellow area) is considered. 


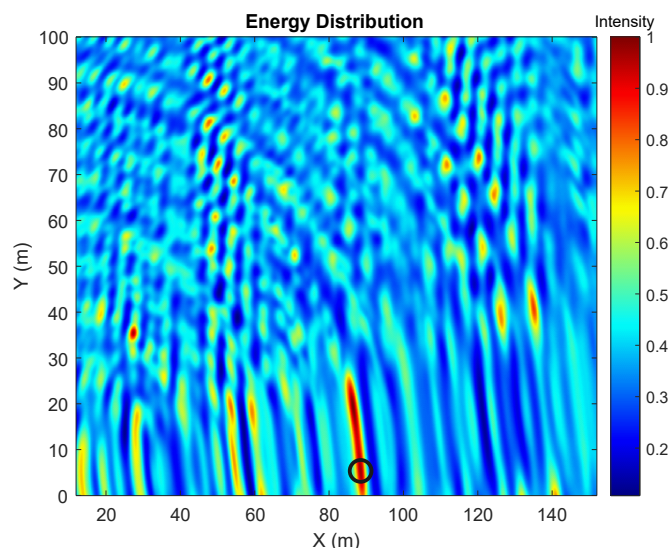

(a)

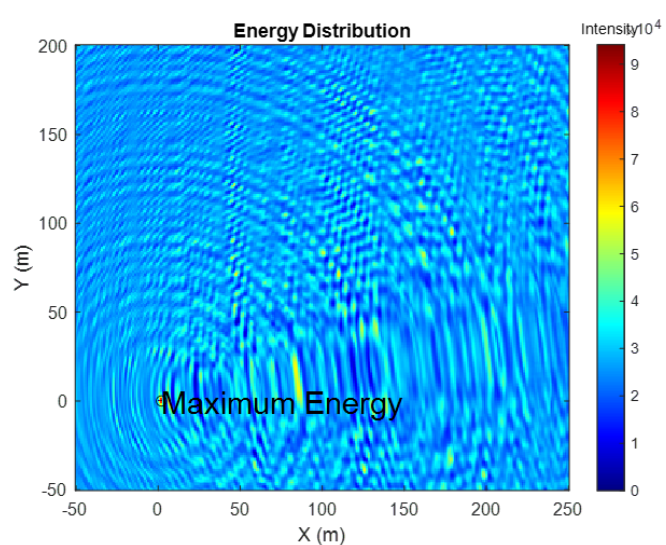

(b)

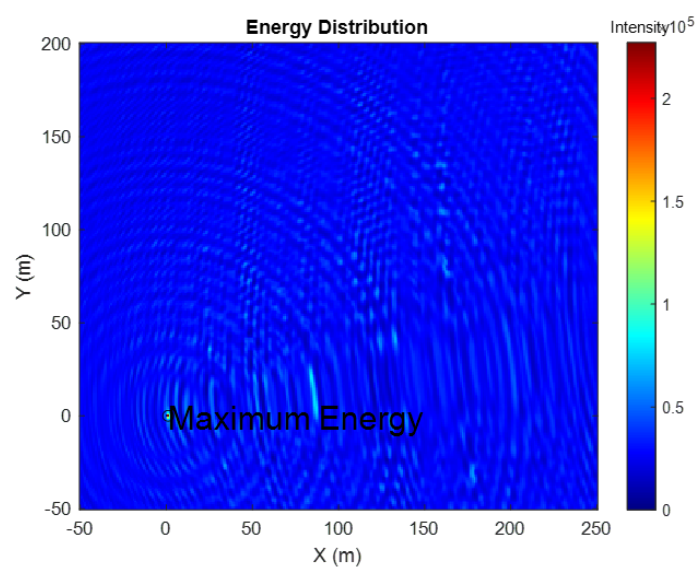

(c)

Figure 12. The ambiguity surface to locate the target based on the Cartesian coordinate system using the proposed estimator and different propagation models at a depth of $24.2 \mathrm{~m}$. (a) Ambiguity surface of MFP with normal-mode model. (b) Ambiguity surface of MFP with image model. (c) Ambiguity surface of MFP with Lloyd-mirror pattern.

Table 5. The estimated location of the target by the proposed estimator with different models for the CMA CGM BRAZIL ship noise.

\begin{tabular}{cccc}
\hline Propagation Model & $\begin{array}{c}\text { Estimated Target } \\
\text { Location }(\mathbf{x}, \mathbf{y}, \mathbf{z})\end{array}$ & $\begin{array}{c}\text { The Horizontal } \\
\text { Range Relative Error }\end{array}$ & $\begin{array}{c}\text { The Radial Range } \\
\text { Relative Error }\end{array}$ \\
\hline Normal-mode $^{(\mathrm{F})}$ & $(88 \mathrm{~m}, 4 \mathrm{~m}, 24.2 \mathrm{~m})$ & $5.2786 \%$ & $3.8774 \%$ \\
Image $^{(\mathrm{F})}$ & $(0 \mathrm{~m}, 0 \mathrm{~m}, 24.2 \mathrm{~m})$ & $100 \%$ & $55.65 \%$ \\
Lloyd-mirror $^{(\mathrm{F})}$ & $(0 \mathrm{~m}, 0 \mathrm{~m}, 24.2 \mathrm{~m})$ & $100 \%$ & $55.65 \%$ \\
Normal-mode $^{(\mathrm{S})}$ & $(85 \mathrm{~m}, 19 \mathrm{~m}, 24.2 \mathrm{~m})$ & $6.3467 \%$ & $4.7295 \%$ \\
Image $^{(\mathrm{S})}$ & $(91 \mathrm{~m}, 6 \mathrm{~m}, 24.2 \mathrm{~m})$ & $1.90 \%$ & $1.19 \%$ \\
Lloyd-mirror $^{(\mathrm{S})}$ & $(91 \mathrm{~m}, 6 \mathrm{~m}, 24.2 \mathrm{~m})$ & $1.90 \%$ & $1.19 \%$ \\
\hline
\end{tabular}

\section{Conclusions}

In this paper, a new technique was presented based on the use of ambient noise as a type of secure signaling. The proposed technique prevents the negative impact of active sonar on the hearing of underwater animals, and as such it is an environmentally friendly solution. Additionally, using the propeller noise is more secure than active sonar, and consumes less energy. The signal generated by the rotation of the propellers of moving ships can act as a sonar signal source and as an opportunistic noise source that detects the position of the target by receiving its scattering from the surface of objects using the 
hydrophone arrays. Based on our knowledge, the present work is the first application using the scattering of ship noise towards underwater localization of targets. In this paper, the return echo from the target surface was processed using the proposed MCCC, which is a low complexity time-frequency method based on MFP. A comparison of the algorithm accuracy for different acoustic propagation models was done. The algorithm was validated in a shallow environment on the littoral of North America, and it was demonstrated that a target with radius of $1.6 \mathrm{~m}$ installed at a depth of $25 \mathrm{~m}$ could be detected using the propeller noise from the ship, as well as using the proposed estimator. The simulation results also showed that the proposed MCCC-time-frequency estimator and normal mode model are resistant to aliasing effect and ambient noise.

Although the proposed method does not require an active source, it still has its limitations, because the underwater channel is a non-stationary environment and has a random signature that varies with time. Therefore, a more realistic model of acoustic propagation will improve the localization accuracy. Additionally, an important challenge for the proposed method occurs when more than one ship is in the test area, in which case the noise generated by each ship has a detrimental effect on the signal generated by the propeller of the desired ship. The impact is most severe when the noise signal generated by other ships is in the same frequency band as the original signal, causing interference on the array, and causing positioning errors.

In future work, the proposed estimator will be simplified to a new equation for implementation on the field-programmable gate array (FPGA) board to localize the underwater active source.

Author Contributions: Conceptualization, M.M.H. and S.A.S.; methodology, J.-F.B.; software, M.M.H. and E.M.; validation, J.-F.B., B.M. and S.A.S.; formal analysis, M.M.H. and E.M.; investigation, J.-F.B. and S.A.S.; resources, J.-F.B.; data curation, J.-F.B. and B.M.; writing-original draft preparation, M.M.H. and E.M.; review and editing, E.M., J.-F.B., B.M., M.M.H. and S.A.S.; visualization, M.M.H. and E.M.; supervision, J.-F.B. and S.A.S.; project administration, J.-F.B.; funding acquisition, J.-F.B. All authors have read and agreed to the published version of the manuscript.

Funding: The project was funded by The Offshore Energy Research Association of Nova Scotia, under a project entitled, "Real-Time Detection of Marine Mammals in High-Flow Environments" under grant number 53824 .

Institutional Review Board Statement: Not applicable.

Informed Consent Statement: Not applicable.

Data Availability Statement: Not applicable.

Acknowledgments: We would like to thank to JASCO Applied Sciences Ltd for providing the dataset of this research.

Conflicts of Interest: The authors declare no conflict of interest.

\section{References}

1. Verlinden, C.M. Acoustic Sources of Opportunity in the Marine Environment-Applied to Source Localization and Ocean Sensing. Ph.D. Thesis, University of California, San Diego, CA, USA, 2017.

2. Park, C.; Seong, W.; Gerstoft, P. Geoacoustic inversion in time domain using ship of opportunity noise recorded on a horizontal towed array. J. Acoust. Soc. Am. 2005, 117, 1933-1941. [CrossRef] [PubMed]

3. Tollefsen, D.; Dosso, S.E. Bayesian geoacoustic inversion of ship noise on a horizontal array. J. Acoust. Soc. Am. 2008, 145, 788-795. [CrossRef] [PubMed]

4. Tollefsen, D.; Dosso, S.E.; Knobles, D.P. Ship-of-opportunity noise inversions for geoacoustic profiles of a layered mud-sand seabed. IEEE J. Ocean. Eng. 2008, 45, 189-200. [CrossRef]

5. Knobles, D.P. Maximum entropy inference of seabed attenuation parameters using ship radiated broadband noise. J. Acoust. Soc. Am. 2015, 138, 3563-3575. [CrossRef] [PubMed]

6. Mirzaei Hotkani, M.; Seyedin, S.A.; Bousquet, J.-F. Estimation of the Bistatic Echolocation from Underwater Target Using Ship Noise based on Normal-Mode Model, Signal Processing and Renewable Energy. Signal Process. Renew. Energy SPRE 2020, 5, 1-14.

7. McKenna, M.F.; Ross, D.; Wiggins, S.M.; Hildebrand, J.A. Underwater radiated noise from modern commercial ships. J. Acoust. Soc. Am. 2012, 131, 92-103. [CrossRef] [PubMed] 
8. Viitanen, V.M.; Hynninen, A.; Sipilä, T.; Siikonen, T. DDES of Wetted and Cavitating Marine Propeller for CHA Underwater Noise Assessment. J. Mar. Sci. Eng. 2018, 6, 56. [CrossRef]

9. Jensen, F.B.; Kuperman, W.A.; Porter, M.B.; Schmidt, H. Computational Ocean Acoustics, 2nd ed.; Springer Science and Business Media: Berlin/Heidelberg, Germany, 2011.

10. Zimmer, W.M.X. Principles of Underwater Sound in Passive Acoustic Monitoring of Cetaceans, 3rd ed.; Cambridge University Press: Cambridge, UK, 2011.

11. Hovem, J.M. Underwater acoustics: Propagation, devices and systems. J. Electroceram. 2007, 19, 339-347. [CrossRef]

12. Cobos, M.; Antonacci, F.; Alexandridis, A.; Mouchtaris, A.; Lee, B. A survey of sound source localization methods in wireless acoustic sensor networks. Wirel. Commun. Mob. Comput. 2017, 2017, 3956282. [CrossRef]

13. Wu, P.; Su, S.; Zuo, Z.; Guo, X.; Sun, B.;Wen, X. Time Difference of Arrival (TDoA) Localization Combining Weighted Least Squares and Firefly Algorithm. Sensors 2019, 19, 2554. [CrossRef] [PubMed]

14. Wang, L.; Yang, Y.; Liu, X. A distributed subband valley fusion (DSVF) method for low frequency broadband target localization. J. Acoust. Soc. Am. 2018, 143, 2269-2278. [CrossRef] [PubMed]

15. Wang, L.; Yang, Y.; Liu, X. A cluster-based direct source localization approach for large-aperture horizontal line arrays. J. Acoust. Soc. Am. 2020, 147, EL50-EL54. [CrossRef] [PubMed]

16. Lo, K.W. A matched-field processing approach to ranging surface vessels using a single hydrophone and measured replica fields. J. Acoust. Soc. Am. 2021, 149, 1466-1474. [CrossRef] [PubMed]

17. Mesmoudi, A.; Feham, M.; Labraoui, N. Wireless sensor networks localization algorithms: A comprehensive survey. Int. J. Comput. Netw. Commun. 2013, 45-64. [CrossRef]

18. ] Michalopoulou, Z.-H.; Gerstoft, P.; Caviedes-Nozal, D. Matched field source localization with Gaussian processes. JASA Express Lett. 2021, 1, 064801. [CrossRef]

19. Tran, P.N.; Trinh, K.D. Adaptive Matched Field Processing for Source Localization Using Improved Diagonal Loading Algorithm. Acoust. Aust 2017, 45, 325-330. [CrossRef]

20. Evans, R.B.; Di, X.; Gilbert, K.E. A Legendre-Galerkin spectral method for constructing atmospheric acoustic normal modes. J. Acoust. Soc. Am. 2018, 143, 3595-3601. [CrossRef] [PubMed]

21. Zhang, T.; Yang, T.C.; Xu, W. Channel distortion on target scattering amplitude in shallow water. J. Acoust. Soc. Am. 2019, 146, EL470-EL476. [CrossRef] [PubMed]

22. Ingenito, F. Scattering from an object in a stratified medium. J. Acoust. Soc. Am. 1987, 82, 2051-2059. [CrossRef]

23. Benesty, J.; Chen, J.; Huang, Y. Microphone Array Signal Processing; Springer: Berlin/Heidelberg, Germany, 2018. 